\title{
Factorial optimization of Coagulation-Flocculation process for Abattoir Wastewater using Carica Papaya seed extract as bio-coagulant
}

\author{
Mmasinachi Mary Nweke 1, ${ }^{*}$, Franklin O. Chukwuma ${ }^{2}$, Benson O. Evbuomwan ${ }^{2}$ and Akuma Oji ${ }^{2}$ \\ ${ }^{1}$ World Bank Africa Centre of Excellence in Oilfield Chemicals Research (ACE-CEFOR), University of Port Harcourt, Port \\ Harcourt, Nigeria. \\ 2 Department of Chemical Engineering, University of Port Harcourt, Port Harcourt, Nigeria.
}

Global Journal of Engineering and Technology Advances, 2021, 09(02), 009-016

Publication history: Received on 28 September 2021; revised on 01 November 2021; accepted on 03 November 2021

Article DOI: https://doi.org/10.30574/gjeta.2021.9.2.0143

\begin{abstract}
The objective of this research was to optimize the coagulation-flocculation process for abattoir wastewater by utilizing a bio-coagulant derived from Carica Papaya seed (CPS). The bio-coagulant (CPC) was extracted from the Carica Papaya seed using a $2 \mathrm{M} \mathrm{NaCl}$ solution, and the coagulation-flocculation process was carried out using a bench scale jar test. Applying design expert (13.0.5.0), $2^{3}$ full factorials with 5 center points, the effects of three factors: coagulant dosage $\left(\mathrm{X}_{1}\right), \mathrm{pH}$ of the wastewater $\left(\mathrm{X}_{2}\right)$, and temperature $\left(\mathrm{X}_{3}\right)$ on turbidity reduction efficiency were examined. Applying ANOVA, it was discovered that a linear model best characterizes the process, with a significant $p$-value of 0.0015 , showing that the model is significant. Additionally, the temperature is a significant component in the model, with a pvalue of 0.02 indicating that the temperature is statistically significant. A turbidity reduction efficiency of $90.02 \%$ was attained at the optimum conditions of $0.75 \mathrm{~g} / \mathrm{L}$ of $\mathrm{CPC}, \mathrm{pH}$ of 6 , and temperature of $308 \mathrm{~K}$.
\end{abstract}

Keywords: Optimization; Abattoir; Coagulation; Factorial; Carica Papaya

\section{Introduction}

Wastewater is produced by a combination of domestic, agricultural, commercial and industrial operations, as well as surface runoff or storm water, as well as sewer intake or infiltration, among other things [1]. The abattoir industry is one of the industrial processes that consumes a significant amount of water in the course of its operations and, as a result, generates a significant amount of wastewater. Organic matter, with significant levels of suspended particles, liquid, and fats, are the most significant contaminants in abattoir (slaughter house) effluent [2]. Usually, these wastewaters are not treated and are instead been thrown into the environment and nearby aquatic bodies [3]. The effects of untreated abattoir wastewater discharged into Nigerian water bodies has developed into a substantial cause of environmental concern in recent years [4]. The vast majority of wastewater is toxic, causing health dangers as well as issues with biological life. Some of them have the potential to cause environmental impact. According to the Clean Water Act of 1972, there are rules for wastewater that is deposited into any navigable water body [5] .

Coagulation is defined as "the process by which destabilization of a given colloidal suspension is achieved," according to Bratby [6], "that is, the objective of coagulation is to transcend those elements that enhance the stability of a system state." To promote coagulation, various types of chemicals (coagulants) are added to wastewater to encourage destabilization of the particulate charges and aggregation of the individual colloidal particles resulting from the destabilization of the particle charges. Several researchers and experts have effectively applied adsorption and coagulation/flocculation as wastewater treatment methods, and they have been able to treat wastewater from a wide

\footnotetext{
* Corresponding author: Mmasinachi Mary Nweke

World Bank Africa Centre of Excellence in Oilfield Chemicals Research (ACE-CEFOR), University of Port Harcourt, Port Harcourt, Nigeria.
}

Copyright (C) 2021 Author(s) retain the copyright of this article. This article is published under the terms of the Creative Commons Attribution Liscense 4.0. 
range of industrial sources, according to the latest information available from sources. Coagulants are substances that are added into wastewater in order to aid in the development of flocs during the coagulation process. There are many different forms of coagulants available (most of which are chemical-based) for wastewater treatment today, depending on their composition, mineral coagulants or organic coagulants may be employed but the most commonly utilized are alum or ferric sulphate [7]. These chemical coagulants have significant disadvantages as well, including $\mathrm{pH}$ alteration, a large amount of sludge resulting in a high disposal cost, inability to function properly in low-temperature water, and a high acquisition cost for the chemicals [8]. Because of the drawbacks connected with the use of chemical coagulants, various studies have investigated the use of alternative coagulants that are environmentally benign, biodegradable, and have the potential to solve the drawbacks associated with the use of chemical coagulants. Many studies have highlighted the viability of using coagulants derived from proteins, polymers, and starches to reduce suspended particles in water through physical methods, and this is validated by the literature [9]. Natural coagulants of plant and animal origin are of significant interest because they are readily available, low-cost natural products that are distinguished by their environmental sustainability and thus are believed to be harmless to humans. Their availability (especially those derived from plants as opposed to those derived from animal coagulants) also suggests they could be possible substitutes for chemical coagulants, and from literature, they have now garnered widespread acceptance throughout the years as a result of their effectiveness [10].

There have been numerous reports of factors that influence the coagulation process; turbidity, pH, alkalinity or acidity, organic matter and temperature are all factors to consider [11]. The factors listed above have a tendency to influence the rate at which suspended particles adhere to the surface of the coagulant [12].

Papaya, scientifically known as Carica papaya, is a lozenge-shaped fruit crop that can be found in a variety of colors, including orange-red, yellow-green, and yellow-orange, and that has a creamy orange flesh [13]. It contains a high concentration of three potent antioxidant vitamins (C, A, and E); as well as minerals ( magnesium and potassium;) The B vitamin pantothenic acid, as well as folate and fiber, are essential [14]. Despite its appearance, the papaya's black seeds are edible and also have a strong, spicy flavor. Fatty acids, crude fiber, crude proteins, and papaya oil are among the chemical constituents [15].

The purpose of this work is to use optimization technique to establish the optimal operating variables for coagulant dose, $\mathrm{pH}$ and temperature as process variables in the turbidity reduction of abattoir wastewater.

\section{Material and methods}

\subsection{Wastewater sample}

The wastewater was fetched from Kwata abattoir Awka, Anambra state, Nigeria (Latitude: $N 6^{0} 12^{\prime} 46.2456^{\prime \prime} E 7^{0} 03^{\prime} 29.6424^{\prime \prime}$ ) with a 10 -litre plastic bottle that was properly cleansed and rinsed with the effluent sample before the sample collection. The parameters of the wastewater were measured and recorded (Table 2), turbidity was measured with digital turbidity, model WGZ-1B power $120 \mathrm{~V}$, pH with Phep-pocket-sized pH meter Hanna instrument, conductivity with conductivity meter model DDS-22C, England and viscosity with viscometer model NDJ-5S, England.

\subsection{Carica Papaya seed (CPS) sample}

The CPS was obtained from local fruit seller at Eke Awka main market in Anambra state. For one week, the CPS was exposed to sunlight to dry, ground using electric grinding machine. The moisture content, crude fiber, crude protein, crude fat, ash content and carbohydrate were determined using AOAC [16], the bio-coagulant (CPC) was extracted using $2 \mathrm{M} \mathrm{NaCl}$ following the method described by Okey-onyesolu et al. [17].

\subsection{Experimental procedure}

Standard bench scale jar test was used for the coagulation-flocculation analysis, the CPC was varied in the range of $0.25-1.25 \mathrm{~g} / \mathrm{L}$, pH of the wastewater was adjusted in the range of $2-10$ by the addition of $1 \mathrm{M} \mathrm{HCL} \mathrm{or} \mathrm{NaOH}$ solutions [18]. and the temperature varied in the range of $298-318 \mathrm{~K}$ using $250 \mathrm{ml}$ of the wastewater sample. At 250 $\mathrm{rpm}$, the samples were vigorously agitated for 2 minutes. It was then followed by another 20 minutes of gradual mixing at $30 \mathrm{rpm}$, then the sample was allowed to settle for 30 minutes. From a depth of $2 \mathrm{~cm}, 20 \mathrm{ml}$ of samples was pipetted in to the $50 \mathrm{ml}$ plastic containers, and the residual turbidity was assessed. The reduction efficiency (R) was determine using equation 1 . 


$$
\% R=\frac{T_{i}-T_{f}}{T_{f}} * \frac{100}{1}
$$

Where, $\mathrm{T}_{\mathrm{i}}$ is the initial Turbidity (Before coagulation) and $\mathrm{T}_{\mathrm{f}}$ is the final Turbidity after coagulation.

\subsection{Experimental design and statistical analysis}

The factors being considered in this work are; coagulant dosage $\left(\mathrm{x}_{1}\right), \mathrm{pH}$ of the wastewater $\left(\mathrm{x}_{2}\right)$ and temperature ( $\left.\mathrm{x}_{3}\right)$, while reduction efficiency was taken as the response. The 3 factors with their ranges and levels are shown in Table 1.

Table 1 Factor ranges and levels utilized in the optimization process

\begin{tabular}{|c|l|c|c|c|c|c|c|}
\hline Factor & Name & Units & Minimum & Maximum & Coded Low & Coded High & Mean \\
\hline A & Dosage & (g/L) & 0.2500 & 1.25 & $-1 \leftrightarrow 0.25$ & $+1 \leftrightarrow 1.25$ & 0.7500 \\
\hline B & $\mathrm{pH}$ & & 2.00 & 10.00 & $-1 \leftrightarrow 2.00$ & $+1 \leftrightarrow 10.00$ & 6.00 \\
\hline C & Temperature & K & 298.00 & 318.00 & $-1 \leftrightarrow 298.00$ & $+1 \leftrightarrow 318.00$ & 308.00 \\
\hline
\end{tabular}

An experimental design involving $2 \mathrm{k}$ factorial implies that 2 levels of $\mathrm{k}$ factors are varied, multiple tests can be done for a given combination of the $\mathrm{k}$ factors, replicas, or $\mathrm{r}$, are the term for this [19] as a result, the total number of runs is given as;

$$
N=r * 2^{k}+C(2)
$$

Where $\mathrm{N}$ is the number of runs, $\mathrm{r}$ is the number of replicas, $\mathrm{k}$ is the number of factors being considered and $\mathrm{c}$ is the center points. In this work, $r=1, k=3$, and $c=5$, given a total of 13 runs. For a first-order model comprising of 3 parameters and their interactions terms, the polynomial equation describing the model is given as;

$$
Y=b_{0}+b_{1} x_{1}+b_{2} x_{2}+b_{3} x_{3}+b_{12} x_{1} x_{2}+b_{13} x_{1} x_{3}+b_{23} x_{2} x_{3}+b_{123} x_{1} x_{2} x_{3}(3)
$$

Where; $\mathrm{Y}$ is the response (Reduction turbidity), $b_{0}$ is the results' average value, $b_{1}, \mathrm{~b}_{2}, \mathrm{~b}_{3}$, $=$ are the linear coefficients, $b_{12}, \mathrm{~b}_{13}, \mathrm{~b}_{23}$ and $\mathrm{b}_{123}$ are the interaction coefficients, while $x_{1}, x_{2}$, and $x_{3}$ are the factors being considered, while $x_{1} x_{2}$, $x_{1} x_{3}, x_{2} x_{3}$ and $x_{1} x_{2} x_{3}$

\section{Results and discussion}

\subsection{Abattoir Wastewater Parameters}

Table 2 demonstrates that the turbidity detected in the abattoir wastewater exceeds the standards for effluent discharge into water or on land [20], indicating that the wastewater should be treated before being discharged into water or onto

\begin{tabular}{|c|c|}
\hline Parameter & Values \\
\hline Turbidity (NTU) & 882 \\
\hline Conductivity $(\mathrm{ms} / \mathrm{cm})$ & 202.2 \\
\hline $\mathrm{pH}$ & 6.4 \\
\hline Viscosity $\left(\mathrm{m}^{2} / \mathrm{s}\right)$ & 143.2 \\
\hline
\end{tabular}
land.

Table 2 Abattoir Wastewater Parameters 


\subsection{Characterization of the Coagulant}

Table 3 lists the physio-chemical features of the CPS, as well as their nutritional value. The substantial protein and carbohydrate content of the seeds indicate that they have a high likelihood of being effective active coagulants in the treatment of abattoir wastewater [21].

Table 3 Proximate and Ultimate Analysis of Papaya seed

\begin{tabular}{|l|c|}
\hline Parameter & Values \\
\hline Moisture content (\%) & 7.75 \\
\hline Ash content (\%) & 16.010 \\
\hline Fat content (\%) & 1.737 \\
\hline Crude Protein (\%) & 6.65 \\
\hline Crude fibre (\%) & 3.182 \\
\hline Carbohydrate (\%) & 64.671 \\
\hline
\end{tabular}

\subsection{Summary of model statistic}

Experiments were carried out in accordance with the design in Table 1, and the corresponding results are presented in Table 4.

Table 4 Design matrix in coded units and the experimental output (responses)

\begin{tabular}{|c|c|c|c|c|c|}
\hline & & Factor 1 & Factor 2 & Factor 3 & Response 1 \\
\hline Std & Run & A:Dosage & B:pH & C:Temperature & Reduction Efficiency \\
\hline & & (g/L) & & K & (\%) \\
\hline 9 & 1 & 0.000 & 0.000 & 0.000 & 84.35 \\
\hline 6 & 2 & 1.000 & -1.000 & 1.000 & 91.72 \\
\hline 12 & 3 & 0.000 & 0.000 & 0.000 & 84.47 \\
\hline 4 & 4 & 1.000 & 1.000 & -1.000 & 80.27 \\
\hline 5 & 5 & -1.000 & -1.000 & 1.000 & 90.93 \\
\hline 2 & 6 & 1.000 & -1.000 & -1.000 & 81.07 \\
\hline 10 & 7 & 0.000 & 0.000 & 0.000 & 90.02 \\
\hline 3 & 8 & -1.000 & 1.000 & -1.000 & 81.52 \\
\hline 1 & 9 & -1.000 & -1.000 & -1.000 & 89.91 \\
\hline 13 & 10 & 0.000 & 0.000 & 0.000 & 83.33 \\
\hline 11 & 11 & 0.000 & 0.000 & 0.000 & 91.16 \\
\hline 8 & 12 & 1.000 & 1.000 & 1.000 & 88.44 \\
\hline 7 & 13 & -1.000 & 1.000 & 1.000 & \\
\hline
\end{tabular}

Table 5 presents a summary of the models for optimization process. The linear model has an adjusted $\mathrm{R}^{2}$ of 0.7397 , and a predicted $R^{2}$ of 0.700 . A model is considered adequate if the difference between the adjusted $R^{2}$ and the predicted $R^{2}$ is less than 0.2. Based on the data in the table, the variation between the adjusted $R^{2}$ and the predicted $R^{2}$ is 0.0396 , indicating that the linear model described the research designs better than the other models.

A model should have the lowest standard deviation (SD) and PRESS (prediction error sum of squares; this metric indicates how well the model is effective in predicting the responses in a new experiment; a low SD indicates a higher correlation between the observed (experimental) and predicted data from the model. The linear model has lower SD and PRESS values, indicating that it more accurately captures the design than other models [22]. 
Table 5 Summary of model Statistics

\begin{tabular}{|c|c|c|c|c|c|c|}
\hline Source & Std. Dev. & $\mathbf{R}^{\mathbf{2}}$ & Adjusted $\mathbf{R}^{\mathbf{2}}$ & Predicted R $^{\mathbf{2}}$ & PRESS & \\
\hline Linear & 2.36 & 0.8048 & 0.7397 & 0.7000 & 77.35 & Suggested \\
\hline 2FI & 2.78 & 0.8206 & 0.6411 & 0.2384 & 196.34 & \\
\hline Quadratic & 2.97 & 0.8291 & 0.5898 & -0.1304 & 291.39 & Aliased \\
\hline
\end{tabular}

\subsection{Analysis of variance (ANOVA)}

The ANOVA analyzes the preferred model in detail; as shown in Table 6, F-value of 12.37 as well as P-value of 0.0051 (less than 0.05 ) reflect the fact that the model is statistically significant; additionally, the temperature term has a Pvalue less than 0.05 , denoting that it is indeed a significant term; and the LOF (lack of fit) value of 1.41 signifies that the LOF is not significant relative to the pure error, implying that the model is good.

Table 6 ANOVA for the selected model

\begin{tabular}{|l|c|l|c|c|c|c|}
\hline Source & Sum of Squares & $\mathbf{d f}$ & Mean Square & F-value & p-value & \\
\hline Model & 207.46 & 3 & 69.15 & 12.37 & 0.0015 & Significant \\
\hline A-Dosage & 2.44 & 1 & 2.44 & 0.4367 & 0.5253 & \\
\hline B-pH & 0.1922 & 1 & 0.1922 & 0.0344 & 0.8570 & \\
\hline C-Temperature & 204.83 & 1 & 204.83 & 36.63 & 0.0002 & \\
\hline Residual & 50.33 & 9 & 5.59 & & & \\
\hline Lack of Fit & 9.84 & 5 & 1.97 & 0.1943 & 0.9492 & not significant \\
\hline Pure Error & 40.49 & 4 & 10.12 & & & \\
\hline Cor Total & 257.79 & 12 & & & & \\
\hline
\end{tabular}

Equation 4 depicts the regression model generated by the software, which establishes a link between the responses and the variables in terms of the coded factor.

$$
\text { Reduction efficiency }(\%)=85.83+0.5525 x_{1}-0.1550 x_{2}+5.06 x_{3}(4)
$$

Equation 4 (coded equation) could be used to predict whether each factor will have a high or low effect on the output response. It could also be used to identify the relative impact of the dependent variable (factors) by comparing the variable coefficients. The coefficients of the factors show that the temperature term, with the highest coefficient of 6.49, has a greater impact on the output response (reduction efficiency) than dosage and pH of the effluent.

\subsection{Validity of the model}

The suggested model's adequacy is then determined using the diagnostic checks offered by Fig. 1 (a) Normal plot of residuals, (b) plot of residuals vs predicted, (c) plot of residuals vs Run, and (d) Plot of predicted vs Actual data. 


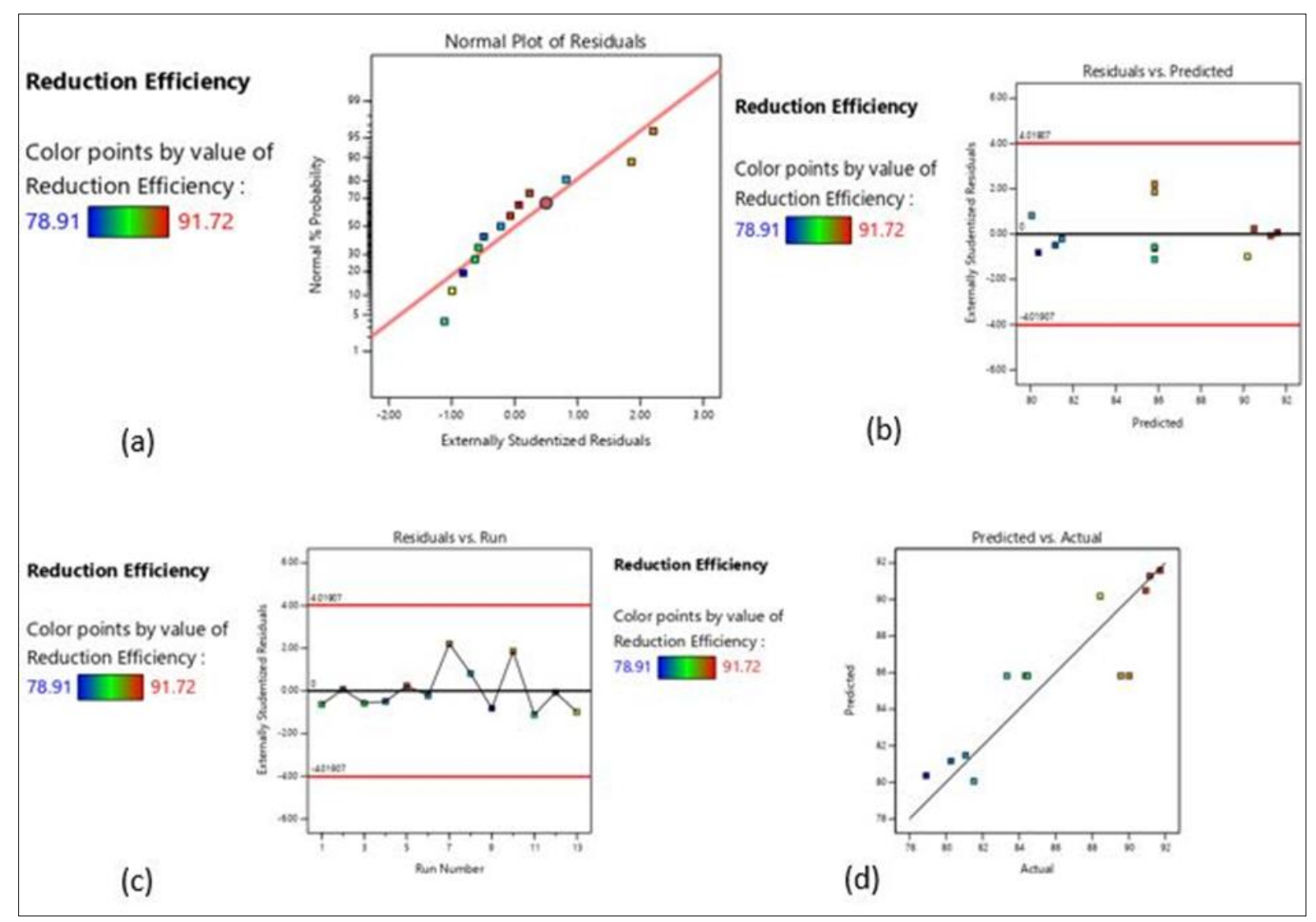

Figure 1 (a) Normal plot of residuals (b) plot of residuals vs predicted (c) plot of residuals vs run (d) Plot of predicted vs Actual data

The normal plot of residuals (Fig. 1 (a)) was used to evaluate the suitability of the selected model; it can be seen from the plot that the data points are approximately linear, with the exception of one data point. As a result, it can be assumed that the error terms have a normal probability distribution. As per the plot of residuals versus runs presented in Fig.1 (b), data points are randomly distributed within the design space, with no data points exceeding the upper and lower range limits, indicating that the model is adequate. The same is true for the plot of residual vs predicted values (Fig. 1 (c)). According to Fig. 1 (d) the data points are distributed along a diagonal straight line, indicating that the actual values and the predicted values are linearly related.

\subsection{Interaction effects between factors}

The interaction and cumulative effects of the process factors on the output (reduced efficiency) were examined utilizing 3D surface plots and contour surface plots, respectively, to determine the response (Fig. 2), Considering just one region predominated on the 3D surface plot for pH versus dosage in Fig. 2 (a), it can be concluded that the interaction between $\mathrm{pH}$ and dosage has a little effect on the response at the optimum temperature of $308 \mathrm{~K}$. According to the contour plot (Fig. 2. (b)), raising the CPC from the design point of $0.75 \mathrm{~g}$ to $1.25 \mathrm{~g}$ and the $\mathrm{pH}$ from 6 to 10 has a negligible influence on reduction efficiency, as evidenced by the light change in region color observed when the CPC was raised from the design point of $0.75 \mathrm{~g}$ to $1.25 \mathrm{~g}$. In the interaction involving dosage and temperature depicted in Fig. 2 (c), five zones can be detected, which are as described in the following: blue, pale blue, green, bright orange, and orange regions. It was discovered that the highest reduction efficiency was attained at pH 6 and temperatures ranging between 308 and 318 degrees Celsius. This is consistent with the ANOVA results, which showed that the temperature term has a significant effect on the output response. 


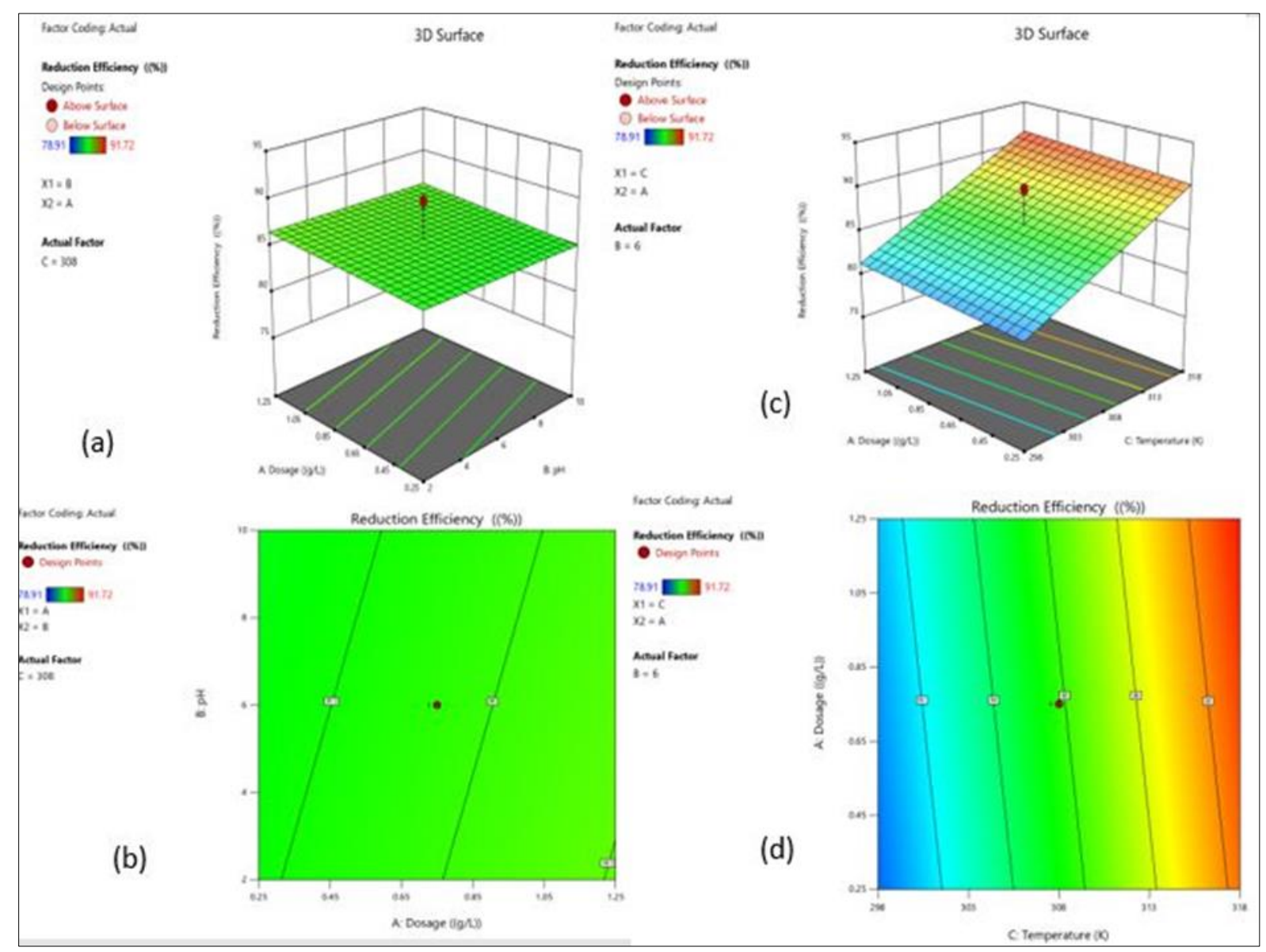

Figure 2 (a) 3D surface plot and (b) Contour plot for pH-dosage. (c) 3D surface plot and (d) Contour plot for Dosage vs temperature

\section{Conclusion}

The optimization of the coagulation-flocculation process for abattoir wastewater utilizing an extract from the Carica Papaya seed has been studied in detail. $0.75 \mathrm{~g} / \mathrm{L}$ of $\mathrm{CPC}, \mathrm{pH}$ of 6 , and temperature of $308 \mathrm{~K}$ were the optimal conditions for turbidity reduction with CPC in the investigation. It was possible to achieve a reduction efficiency of $90 \%$ under these conditions. The linear model with a difference of 0.0398 , which is less than 0.2 , is the model that maximizes the adjusted $\mathrm{R}^{2}$ and predicted $\mathrm{R}^{2}$, and the model's p-value of 0.0015 and F-value of 12.37 indicate that the model is statistically significant. Therefore, CPC an environmentally acceptable bio-coagulant, can be utilized as an alternative to chemical coagulants in the treatment of abattoir effluent to reduce turbidity levels.

\section{Compliance with ethical standards}

\section{Acknowledgments}

The authors express their appreciation to the World Bank Africa Centre of Excellence in Oilfield Chemicals Project (ACECEFOR) at the University of Port Harcourt in Port Harcourt, Nigeria, for their assistance throughout this study. Special thanks to Engr. Dr. Marcel Ejimofor, who assisted with the experimental work.

\section{Disclosure of conflict of interest}

The authors declare that they have no competing interests.

\section{References}

[1] Tilley E. Compendium of sanitation systems and technologies. Eawag. 2014. 
[2] Eryuruk K, U Tezcanun, Ogutveren U. Bakir. Electrocoagulation in a Plug flow Reactor: the treatment of cattle Abattoir wastewater by Iron rod anodes. 2014; 461-468.

[3] Effendi H, Sari RD, Hasibuan S. Moringa oleifera as coagulant for batik effluent treatment. In35th Annual Conference of the International Association for Impact Assessment, Firenze Fiera Congress and Exhibition Center, Florence. 2015.

[4] Chukwuma EC, Orakwe LC, Ugwuishiwu BO, Nwoke OA, Igbokwe E. GIS hotspot application and use of set-cover problem for centralized abattoir biogas plant treatment facilities in Anambra State of Nigeria. Agricultural Engineering International: CIGR Journal. 2018; 20(4): 63-8.

[5] Nair AT, Ahammed MM. The reuse of water treatment sludge as a coagulant for post-treatment of UASB reactor treating urban wastewater. Journal of Cleaner Production. 1 Jun 2015; 96: 272-81.

[6] Bratby J. Coagulation and flocculation. Uplands: Croydon, England. 1980.

[7] Ahmad AL, Ismail S, Bhatia S. Optimization of coagulation- flocculation process for palm oil mill effluent using response surface methodology. Environmental science \& technology. 15 Apr 2005; 39(8): 2828-34.

[8] Shan TC, Al Matar M, Makky EA, Ali EN. The use of Moringa oleifera seed as a natural coagulant for wastewater treatment and heavy metals removal. Applied Water Science. Jun 2017; 7(3): 1369-76.

[9] Silva MJ, Paterniani JE, Francisco AR. Application of Moringa Oleifera natural coagulant for clarification and disinfection of treated wastewater in wetlands and multistage filtration. African Journal of Agricultural Research. 27 Jun 2013; 8(24): 3102-6.

[10] Choy SY, Prasad KM, Wu TY, Ramanan RN. A review on common vegetables and legumes as promising plantbased natural coagulants in water clarification. International journal of environmental science and technology. 1 Jan 2015; 12(1): 367-90.

[11] Dempsey BA, Sheu H, Ahmed TT, Mentink J. Polyaluminum Chloride and Alum Coagulation of Clay-Fulvic Acid Suspensions. Journal-American Water Works Association. Mar 1985; 77(3): 74-80.

[12] Menkiti MC, Ejimofor MI, Ezemagu IG, Uddameri V. Turbid-metric approach on the study of adsorptive component of paint effluent coagulation using snail shell extract. Arabian Journal for Science and Engineering. Jul 2016; 41(7): 2527-43.

[13] Aravind G, Bhowmik D, Duraivel S, Harish G. Traditional and medicinal uses of Carica papaya. Journal of medicinal plants studies. 2013; 1(1): 7-15.

[14] Parle M, Gurditta A. Basketful benefits of papaya. Int. Res. J. Pharm. Jul 2011; 2(7): 6-12.

[15] Pal A, Mazumder A. Carica Papaya, a Magic Herbal Remedy. International Journal of Advantages Research (IJAR). 2013; 5(1): 262-35.

[16] Helrich K. Official methods of analysis of the Association of Official Analytical Chemists. Association of official analytical chemists. 1990.

[17] Okey-Onyesolu CF, Chukwuma EC, Okoye CC, Onukwuli OD. Response Surface Methodology optimization of chitoprotein synthesized from crab shell in treatment of abattoir wastewater. Heliyon. 1 Oct 2020; 6(10): e05186.

[18] Igwegbe CA, Onukwuli OD. Removal of total dissolved solids (TDS) from aquaculture wastewater by coagulationflocculation process using Sesamum indicum extract: effect of operating parameters and coagulation-flocculation kinetics. The Pharmaceutical and Chemical Journal. 2019; 6(4): 32-45.

[19] Elhalil A, Tounsadi H, Elmoubarki R, Mahjoubi FZ, Farnane M, Sadiq M, Abdennouri M, Qourzal S, Barka N. Factorial experimental design for the optimization of catalytic degradation of malachite green dye in aqueous solution by Fenton process. Water Resources and Industry. 1 Sep 2016; 15: 41-8.

[20] NER. Standards for Discharge of Effluent into water or on Land. National Environment Regulation. 1999.

[21] Igwegbe CA, Ighalo JO, Onukwuli OD, Obiora-Okafo IA, Anastopoulos I. Coagulation-Flocculation of Aquaculture Wastewater Using Green Coagulant from Garcinia kola Seeds: Parametric Studies, Kinetic Modelling and Cost Analysis. Sustainability. Jan 2021; 13(16): 9177.

[22] Ejimorfor MC. Coagulation treatment of paint wastewater by novel Chito-protein and conversion of post treatment sludge to biogas and carbon dioxide. Ph.D Thesis. 2021. 